Algtewi, E. E., Owens, J., \& Baker, S. R. (2015). Analysing people with head and neck cancers' use of online support groups. Cyberpsychology: Journal of Psychosocial Research on Cyberspace, 9(4), article 6. doi: $10.5817 / C P 2015-4-6$

\title{
Analysing people with head and neck cancers' use of online support groups
}

\author{
Eamar E. Algtewi ${ }^{1}$, Janine Owens ${ }^{2}$, Sarah R. Baker ${ }^{3}$
}

${ }^{1,2,3}$ Academic Unit of Dental Public Health, School of Clinical Dentistry, Sheffield University, Sheffield, United Kingdom

\begin{abstract}
Online support groups have become a familiar source of social support for people with a variety of health issues. To date, no research has investigated the use of such groups by people with head and neck cancer (H\&N). The aim of this study was to assess the types of social support, both sought and offered, within online support groups (OSGs) for head and neck cancer. Data was collected from 18 OSGs and two coding schemes; the Social Support Behaviour Code and the scheme of Coursaris \& Liu (2009), were used to analyse the content of support-seeking and support-offering messages. The results suggested that the most frequently offered types of social support by group members were informational (43.4\%) and emotional (32.4\%), followed by esteem (15.6\%) and network support (6.1\%), whereas little tangible assistance was offered (2.4\%). The content of support-seeking messages included group members sharing personal experience (31.5\%), with the most frequent sought support being informational support (25.5\%). The OSGs can be advantageous to people with H\&N cancer, especially for those with appearance or speech problems to mitigate their embarrassment and facilitate interaction with others. The present findings suggest that such OSGs can be promising sources of H\&N cancer-related informational and emotional support for the recipients, whether they are patients, family members or carers.
\end{abstract}

Keywords: Online support groups, head cancer, neck cancer, social support

\section{Introduction}

Head and neck (H\&N) cancer is commonly cited as the most emotionally traumatic of all cancers, mainly because the outcomes of the disease impact heavily on function and result in numerous psychosocial issues (de Leeuw, de Graeff, Ros, Blijham, et al., 2000; de Leeuw, de Graeff, Ros, Hordijk, et al., 2000; Dropkin, 2001; McDonough, Boyd, Varvares, \& Maves, 1996; National Institute for Clinical Excellence [NICE], 2004). This assertion fails to consider the complexity of health and its links with social support, social relationships, social networks, stress, coping and resilience and their influence on mortality and morbidity.

The study of social relationships and physical health has an extensive theoretical background starting with the work of Durkheim who argued that social environment was strongly linked to suicide rates (Durkheim, 1951). The field of health psychology advanced the area of social networks and health and considered the impact of social support on health (Cobb, 1976). Cobb's work was followed by that of Berkman and Syme whose nine-year longitudinal study argued that social support was strongly linked to mortality rates and people with fewer social ties had higher mortality rates (Berkman \& Syme, 1979). There is now an increasing amount of reliable evidence that links social support to both morbidity and mortality from 
certain diseases and health-related conditions (Holt-Lunstad, Smith, \& Layton, 2010). One factor that appears heavily implicated in the protective nature of social relationships is stress.

Early work on stress was conceptualised entirely in biomedical terms and the 'fight or flight' response, whereas later research in the 1960s and 1970s began to address the complexity of the concept and the ways it was perceived in numerous ways by different people (Antonovsky, 1979; Lazarus, 1976). Lazarus and Folkman addressed this complexity by developing a transactional model of stress and coping as a framework for evaluating the processes involved in coping (Lazarus \& Folkman, 1984). This framework generated a substantial number of studies which explored a variety of coping mechanisms and adjustment to illness for numerous health related conditions, particularly cancer (Stanton, Revenson, \& Tennen, 2007).

\section{Coping with Cancer}

People with different types of cancer have been found to use a variety of coping mechanisms to deal with many of the resultant psychosocial issues (Al-Azri, Al-Awisi, \& Al-Moundhri, 2009; Petticrew, Bell, \& Hunter, 2002; Stanton et al., 2000). Within these studies, these coping mechanisms vary and appear dependent on type of cancer, site and degree of impact on function.

For example Stanton and his colleagues (2000) have explored emotional approach coping as a mediator of the relationship between hope and adaptive outcomes in 92 women with breast cancer. They also investigated the interaction of emotional approach coping and social accessibility in predicting adaptive outcomes and found that women who, at the beginning of the study, coped by expressing emotions regarding cancer had fewer medical appointments for cancer-related illnesses, enhanced physical health and vigour, and reduced distress during the following three months compared to women low in emotional expression. More recently, Al-Azri, Al-Awisi \& Al-Moundhri (2009) reviewed the literature on the impact of breast cancer diagnoses and the strategies used by women to cope with this disease and suggest that there are numerous strategies used by women with breast cancer to cope with this disease, including positive cognitive restructuring, emotional expression, wishful thinking, increased religious practice, disease acceptance, yoga and exercise, and family and social support.

Despite the wealth of studies, mainly around breast, lung, liver, stomach and colorectal cancer, which illustrate a variety of strategies on coping, the smaller number of studies for head and neck cancer suggest that patients use particular coping strategies during their cancer journey. For example, emotion or problem-focused coping (Vidhubala, Ravikannan, Mani, Karthikesh, \& Latha 2006), with some studies arguing that problem focused coping is the most frequently used strategy by H\&N cancer patients (Elani, Edgar, \& Allison, 2009; Elani \& Allison, 2011). In contrast, Chaturvedi, Shenoy, Prasad, Senthilnathan, \& Premlatha (1996) claim that helplessness and fatalism are the commonest coping mechanisms used by H\&N cancer patients whilst Sherman, Simonton, Adams, Vural, \& Hanna (2000) suggest that denial, focusing on the illness, emotional ventilation, and behavioural disengagement such as giving up or withdrawing were most characteristic of these patients. More recently, Agarwal, Hamilton, Crandell, \& Moore (2010) suggest that altruism, seeking emotional support from friends and family, and using religion based coping were the most commonly used strategies. The lack of common consensus and variation in these studies may be explained through the different research designs, methodologies and different participant samples employed.

Exploring the ways in which people cope with head and neck cancer is important because of the impact from the visible effects of surgery and the loss of ability to communicate effectively for some people. These effects may create social isolation because of the reductions in social interaction and changes to identity (Gamba et al., 1992; Hagedoorn \& Molleman, 2006; Houston \& Bull, 1994). Social support for people with $H \& N$ cancer appears to be important but their voices and experiences are absent from the literature. For example, one study has explored pre-treatment coping strategies for patients with H\&N cancer and suggests that social support positively influences coping (List et al., 2002). Other studies argue that social support enhances quality of life for people with H\&N cancer, mainly in reducing the impact of anxiety and depression (Howren, Christensen, \& Karnel, 2011; Chueh et. al, 2009; Karnell, Christensen, Rosenthal, Magnuson, \& Funk, 2007). The type of social support that was explored in these studies was in its traditional offline face-to-face form using questionnaires and face-to-face structured interviews. However, the recent rise in technology and online social networking means that there has been a move towards using online groups as a way of searching for information and garnering support for different aspects of health (Coulson, 2005). 
Although no study so far has explored the differences in coping mechanisms used by patients with dissimilar types of cancer, it appears from the findings of the previous studies that people with H\&N cancer use general coping strategies such as increased religious practices and social support which is similar to those used by breast cancer patients. Patients with H\&N cancer also use other strategies that appear to be different from those used by patients with breast cancer. These appear to be more negative and may be related to altered appearance, eating and communication problems associated with the outcomes of $\mathrm{H} \& \mathrm{~N}$ cancer treatment. These differences in outcomes may have implications for the ways in which people with H\&N cancer use support groups.

\section{Online Support Groups}

Today, many people use the internet to research a variety of health conditions and there are an increasing number of online support groups (OSGs) available for different health conditions, including cancer (Eysenbach, Powell, Englesakis, Rizo, \& Stern, 2004). Studies of different health conditions, such as HIV/AIDS, Huntington's disease and irritable bowel syndrome (IBS), suggest that OSGs may satisfy a need for emotional support from others who share a common experience, but identify that the groups also offer anonymity, convenience and accessibility (Braithwaite, Waldron, \& Finn, 1999; Coulson, 2005; Coulson, Buchanan, \& Aubeeluck, 2007; Finn, 1999; Mo \& Coulson, 2008; White \& Dorman, 2000; Winzelberg, 1997). Although online support groups are popular, the scientific evidence regarding their effectiveness in helping participants cope with health-related problems is not convincing and it has been suggested by some researchers that the quality and quantity of interactions may be involved in healthrelated outcomes; for example, emotional support enhancing members' relationships with one another or the group as a whole, whereas informational support only satisfied short term needs (Wang, Kraut, \& Levine, 2012).

Studies of different health conditions have tended to investigate the role of OSGs for health conditions that were curable or exhibited good prognoses and survival rates. In contrast, $\mathrm{H} \& \mathrm{~N}$ cancer has a poor prognosis and a low survival rate $(<50 \%)$ which has not improved for thirty years (Karim-Kos et al., 2008). In the UK alone, there were 6,767 new cases and 2119 deaths in 2011 from H\&N cancer and global incidences of H\&N cancer are rising (Ferlay et al., 2015). Coupled with low survival rates are the issues related to altered facial appearance from surgery which may involve removal of part of the upper or lower jaw, nose, and ear and occasionally removal of an eye followed by reconstruction and additional functional impacts from the treatment of $H \& N$ cancer (Tolentino et al., 2011). For example, functional impacts such as ulcerated, dry and sore mouth from radiation therapy, medication, or surgery can result in loss of or alteration of speech (Tolentino et al., 2011), altered facial appearance resulting from surgery may create problems with social interaction (Rogers, Hannah, Lowe, \& Magennis, 1999), dry and sore mouth and removal of part of the jaw or tongue can create issues with eating and socialising (van Cann, Dom, Koole, Merkx, \& Stoelinga, 2005). Alterations in facial appearance and verbal communication may make participation in a conventional face-to-face support group more challenging for some people depending on the degree of impact of the surgery and treatment. These challenges appear specific to people with $\mathrm{H} \& \mathrm{~N}$ cancer. If we consider the challenges alongside findings of previous studies about coping with H\&N cancer (offline) compared to coping with other types of cancer, we could suggest that coping for patients with H\&N cancer might work differently. Although there have been a few face-to-face studies, mostly about quality of life for people with head and neck cancer, to date, there have been no studies which assess the types of online social support that are sought by or offered to people with H\&N cancer. We could infer that coping with H\&N cancer using online support may also differ from other types of cancer.

\section{Aim}

The aim of this study was to assess the types and frequency of social support, sought and offered, within OSGs for people with H\&N cancer.

\section{Methods}

\section{Procedures}

Data was obtained from messages posted to online H\&N cancer groups. A thorough search was performed on Google using a set of key words related to OSGs and H\&N cancer (Head, neck, cancer, tumour, forum, online, message boards, support group, chat, blog, oral, pharyngeal, laryngeal, lip, tongue, tonsil, throat, gingival, gum, mouth, dental, cheek, epiglottis) in December 2011. A total of 56 online H\&N cancer 
groups, where no registration was required, were identified for the purposes of the study. Of the 56 groups, 38 were excluded by the study exclusion criteria (outlined in Figure 1) and the moderators of the 18 remaining groups were contacted to explain the research study and to seek their permission to recruit participants from their group. Interestingly, these 18 groups were found to be led by the same 6 moderators and all of them provided permission. Subsequently the data were collected from these 18 groups.

Data were selected in each of these groups for the even months in the year 2011 (February, April, June, August, October and December) by selecting one random posting and its associated reply messages from each month using an electronic Random Number Generator (Haahr, 1998). The total sample consisted of 108 support-seeking messages yielding 527 reply messages (support-offering messages). However, after application of the exclusion criteria to types of messages, those remaining totalled 87 support-seeking messages and 312 support-offering messages (see Figure 1).

In spite of the availability of many OSGs for H\&N cancer, only a few of them were active with daily messaging. The activity of the remaining groups was very varied, but some groups did not have any messages posted for a full month. In order to ensure that as many OSGs were included as possible, but still include those that were active, a cut-off criterion was applied of at least one posting per month (i.e. at least 12 postings per year). Therefore, the number of messages per month varied between the 18 groups (from a few messages to thousand). In addition, the groups were selected regardless of the number of members which varied from 20 to 300 members. Each group had a moderator who accepted each new member and monitored the content of the group.

\section{Sample Characteristics}

Seventy-eight unique names were identified as posting 87 support-seeking messages, and 125 unique names were identified as senders of the 312 reply (support-offering) messages to those postings. Most members were from the USA, UK, Australia and Canada. The age of 80 members could be identified; $67.5 \%$ were above 40 years of age and gender could be identified for 180 members; $68 \%$ were females.

The cancer type of 178 members could be identified, with 90 (50.5\%) being oral cancer, $36(20.2 \%)$ pharyngeal cancer and $2(1.1 \%)$ laryngeal cancer, whereas the remainder were mixed cancers. In addition, information about the stage of cancer was available for 73 members; two thirds of them were in advanced stages (Stage III and Stage IV). Similarly, the treatment stage could be identified for 184 members with the majority $(73.5 \%)$ being in post-treatment stages.

\section{Ethical Approval}

The moderators of the groups were contacted by email, phone, post, Facebook or directly through their "contact us" form explaining the research study and confirmation of their permission was sought to recruit participants from their group. Moderators informed group members of the study. The online groups that were used did not require any registration or subscription by the researchers to view the messages and were considered to be in the public domain (Coulson, 2005; Eysenbach \& Till, 2001; Flicker, Haans \& Skinner, 2004). Despite being in the public domain, all data were anonymised, pseudonyms provided for each message and any details deemed to be particularly identifiable (names, places of residence, unusual contexts) removed to protect participants.

\section{Coding Frames}

Sought and offered social support within each message was examined using content analysis. This method allowed the messages to be classified according to a priori determined social support dimensions. A modified form of the Social Support Behaviour Code (SSBC) (Cutrona \& Suhr, 1992) was used in the present study (Mo \& Coulson, 2008). This modified version is for use with online support groups and consists of 21 items. The coding frame evaluates the rate of support-offering behaviours that exist in five main classes (Table 1 ). 
(-) Deals with any oral conditions * $n=1$

(-) Requiring registration $n=4$
(-) No longer active or inactive with less than 12 postings/year $n=23$
(-) Postings with 11 replies (not related to $\mathrm{H} \& \mathrm{~N}$ cancer or not in our definition) $n=4$
(-) At least 1 month with no postings $n=$

10

Remaining $n=18$

$\otimes$

Selected months $n=6$

$\otimes$

Selected postings /month $n=1$

Total postings yielding 527 replies $n=108$
(-) No reply messages $n=11$

(-) Postings with 44 replies (sent before study limit $n=6$

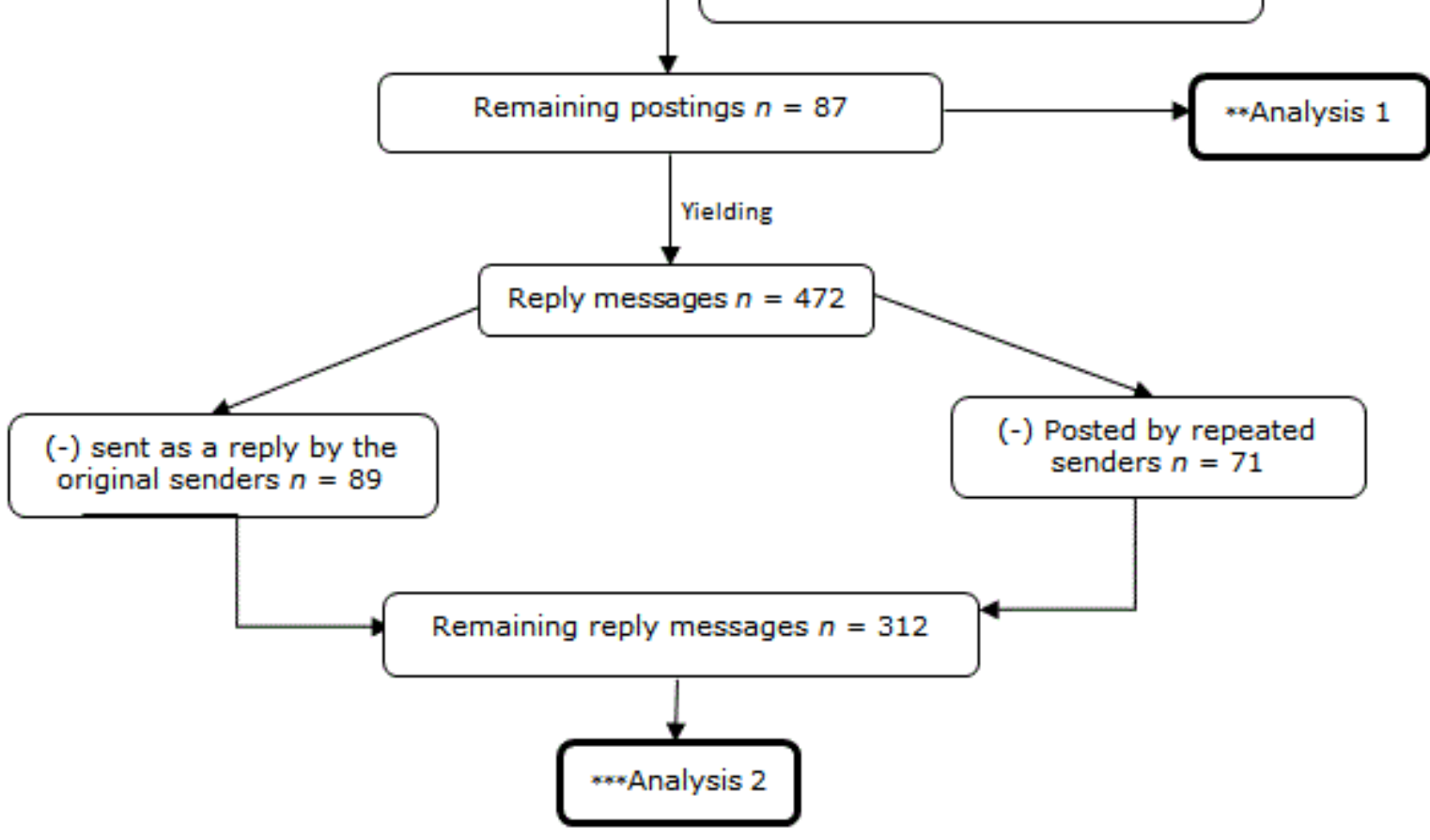

Figure 1: Sample profile. ${ }^{*} n=$ number in sample; $* *$ Analysis $1=$ Analysis of the support-seeking messages using the scheme of Coursaris \& Liu (2009); ***Analysis 2= Analysis of the support-offering messages using the SSBC. 
Table 1. Five Main Dimensions of the SSBC for Coding Support-Offering Messages (Cutrona \& Suhr, 1992).

\begin{tabular}{ll}
\hline Dimension & Description \\
\hline $\begin{array}{l}\text { Informational } \\
\text { support }\end{array}$ & $\begin{array}{l}\text { Offers knowledge and advice related to identity of the stress or how to cope } \\
\text { with that stress }\end{array}$ \\
$\begin{array}{l}\text { Esteem Support } \\
\text { Includes confidence in ability and communicates respect }\end{array}$ \\
$\begin{array}{l}\text { Emotional support } \\
\text { Tangible assistance }\end{array}$ & $\begin{array}{l}\text { Supplies care, love and concern in communication with the recipients } \\
\text { Supplies services or goods required to deal with the stressful condition }\end{array}$ \\
\hline
\end{tabular}

Support-seeking was coded using the scheme of Coursaris \& Liu (2009) (8 items) which classifies messages in 8 dimensions (Table 2).

Table 2. The Scheme of Coursaris \& Liu (2009).

\begin{tabular}{|c|c|}
\hline Dimension & Description \\
\hline Seeking informational support & $\begin{array}{l}\text { Included specific questions concerning the situation to obtain factual } \\
\text { information, evaluate certain situation or to seek suggestions or } \\
\text { advice }\end{array}$ \\
\hline Seeking emotional support & Show emotional or psychological weakness and need for comfort \\
\hline Seeking esteem support & Validation for perspective/relief of blame \\
\hline Seeking network support & Asking for prolonged or contact with others in similar situation \\
\hline Seeking tangible support & $\begin{array}{l}\text { Asking for financial, material, equipment, asking to be shown an } \\
\text { aspect of care on a one-to-one basis }\end{array}$ \\
\hline Sharing personal experiences & $\begin{array}{l}\text { Share personal conditions, thoughts, and feelings related to the } \\
\text { issue with others initially and spontaneously }\end{array}$ \\
\hline Expression of gratitude & $\begin{array}{l}\text { Expressed straightforward thankfulness for the recipient's previous } \\
\text { support }\end{array}$ \\
\hline Congratulations & $\begin{array}{l}\text { Expressed joy or acknowledgment of the recipient's achievement or } \\
\text { good fortune }\end{array}$ \\
\hline
\end{tabular}

\section{Evaluation of Coding Frames}

A pilot study using 20 messages (10 support-seeking and 10 support-offering) assessed the applicability of the coding schemes. These messages were independently coded by three coders; a dentist [EEA], an accredited health psychologist [SRB] and social scientist with extensive fieldwork and methodological experience [JO]. Each of the coders read the original paper of the coding frames as well as subsequent papers that used these frames to develop their existing knowledge. Before conducting the pilot study, the three coders met, discussed and agreed on the way in which the frames were applied and no further training was required. The degree of agreement between the three coders was $80 \%$ and evaluated using Cohen Kappa. As a result of the evaluation, some sub-dimensions were revised. For example, for the support-offering messages, another item (prayer) was added under the emotional support dimension. The final coding system for the support-offering messages consisted of 22 items. 
For support-seeking messages, some messages involved specific questions about how to offer support to others which would not fit into the dimension of "seeking informational support", therefore a new dimension "seeking wellbeing information" was developed. Furthermore, some messages involved expression of concern for others and an additional dimension, "expression of care," was created. Some support seekers tended to send messages of hope and confidence and this led to the creation of another dimension; "encouragement". These three additions meant that the revised coding system contained 11 items. Following these modifications, a further 20 messages were coded independently by the three coders and agreement was calculated to be more than $80 \%$.

\section{Results}

\section{Social Support Provided: Analysis of Support-Offering Messages}

Of a total of 312 support-offering messages, 307 included at least one form of social support. There were 1240 support statements, of which, 71 could not be analysed within the existing framework and another 160 statements were excluded because they included a repeated sub-dimension of social support within the same support-offering message. Therefore, the final number of statements that could be coded under the chosen coding framework was 1009.

The most frequently recorded dimension was informational support (43.4\%), followed by emotional support (32.4\%). The third most frequent dimension of social support was esteem support (15.6\%). However, the frequency of both network support and tangible assistance was found to be low $(6.1 \%$ and $2.4 \%$ of the total support respectively). The frequency of each social support dimension is shown in Table 3. All five dimensions and all except two of the sub-dimensions of social support in the utilised coding framework were found in the messages. Details of each of the dimensions are given with examples.

Informational support. All of the five sub-dimensions that are listed under this dimension of social support were observed with the "sharing own experience" sub-dimension representing the highest percentage (13.6\% of the total). Messages within this sub-dimension contained experiences that acted as references rather than being a tool of education in dealing with H\&N cancers. For example, Alex shared his own experiences as a response to a member who had finished his treatment course and was still suffering from severe cramps in the H\&N region:

Alex:

"I'm 9 years post treatment and still get the occasional neck/jaw cramp although nowhere near as often and they don't last as long; they happen about once or twice a month now. I found solpadol works for me although they take a while to work. They seem to stop the repeat cramps that I get if I don't take anything."

Messages that have been categorised as "advice" under this dimension suggest actions and provide ideas or guidance for coping with H\&N cancer. For example, in response to a member who had treatment for advanced oral cancer and had lost a lot of weight, Martin wrote: "Try to get a good amount of protein and nutrients into you, and try walking outside a bit daily".

The category of 'teaching messages' refers to statements that provide technical information or facts about $\mathrm{H} \& \mathrm{~N}$ cancer-related conditions or about the skills needed to cope with these conditions. For example, a member who was complaining about some symptoms after receiving radiation treatment received this explanation from Clare:

"The condition of your neck swollen, red tender skin and warm to the touch is a common condition called Lymphedema. It is very common for people who had radiation treatment to the affected area".

Situation appraisal messages that try to redefine the condition in a more positive manner and referral messages that act to direct the recipients to a particular resources or expertise are also listed under this dimension but with less relative frequency ( $4.9 \%$ and $3.1 \%$ respectively). 
Table 3. Frequency of Each Social Support Dimension and Sub-Dimension.

\begin{tabular}{|c|c|c|}
\hline Support dimension & Number of messages & $\%$ of messages \\
\hline Informational support & 438 & $43.4 \%$ \\
\hline Advice & 122 & 12.1 \\
\hline Referrals & 32 & 3.1 \\
\hline Situation appraisal & 50 & 4.9 \\
\hline Teaching & 96 & 9.5 \\
\hline Sharing own experience & 138 & 13.6 \\
\hline Esteem support & 158 & $15.6 \%$ \\
\hline Compliments & 85 & 8.4 \\
\hline Validation & 69 & 6.8 \\
\hline Relief of blame & 4 & 0.4 \\
\hline Network support & 61 & $6.1 \%$ \\
\hline Access & 32 & 2.9 \\
\hline Presence & 29 & 2.6 \\
\hline Emotional support & 327 & $32.4 \%$ \\
\hline Expression of care & 42 & 3.1 \\
\hline Relationship & 2 & 0.2 \\
\hline Physical Affection & 31 & 3.1 \\
\hline Confidentiality & 0 & 0 \\
\hline Empathy & 40 & 3.9 \\
\hline Sympathy & 47 & 4.6 \\
\hline Encouragement & 138 & 13.6 \\
\hline Prayer & 27 & 2.6 \\
\hline Tangible assistance & 25 & $2.4 \%$ \\
\hline Loan & 3 & 0.3 \\
\hline Perform direct Task & 5 & 0.5 \\
\hline Express willingness & 17 & 1.6 \\
\hline Perform indirect Task & 0 & 0 \\
\hline Total & 1009 & $100 \%$ \\
\hline
\end{tabular}

Esteem support. The most frequent sub-dimension in this context was "complaints" representing $8.4 \%$ of the total 1009 messages. This kind of support supplied positive statements about the support seeker's activities and/or personality and their ability to cope with their cancer. For example, in response to a member who had finished his treatment but was still experiencing some side effects, Richard wrote:

"Congrats on finishing your treatments and becoming cancer free! You will bounce back, it just takes time. Next year this time you will be so much better than you are now".

Validation messages involved acknowledgment or agreement with the recipient's opinion on the situation related to $\mathrm{H} \& \mathrm{~N}$ cancer including the recipient's emotions, action, beliefs or thoughts. For example, some messages like Tommy's expressed validation of the stress that a member had felt stressed due to waiting for the results of some investigations:

"We all get apprehensive around check-up time. I guess that's a fear we can never quite get past".

Other messages expressed validation and agreement with previous respondents other than the original posters. For example, William posted: 
However, only a few statements $(0.4 \%)$ could be coded under the "relief of blame" sub-dimension. We can suggest here that it could be that people with H\&N cancers do not often see themselves to blame.

Network support. A relatively low percentage of messages (6.1\%) were coded under this dimension of social support and similar percentages of the two sub-dimensions (presence and access) were recorded in the data.

Access messages seemed to invite recipients to participate in a social support group to expand their social network. Presence messages reminded the recipients that the support group acted as a network to provide continuous support, as someone is always available to spend time with them. For example, one member who faced a recurrence of cancer received support from Katherine:

"Please keep posting so we can help support you thru this battle".

Emotional support. This dimension of social support appeared to be the second most frequent in the data and represented about a third of the total messages. The supporting statements that belong to this dimension of support could be categorised under seven items of the coding framework; encouragement, sympathy, empathy, expression of care, physical affection, prayer and relationship.

Encouragement messages were the most frequently seen and tend to provide confidence and hope to the recipient. Nicola responded to one individual with a prosthetic device (obturator) to replace the opening resulting from cancer of the hard palate:

"I hope the opening will be closed in the future".

Some messages contained other expressions of encouragement support such as: "Best wishes", "good luck", "keep the faith" and "good health".

Sympathy messages expressed distress, unhappiness or grief at the situation of the recipient. Eve was supporting a member who was a caregiver to a father with terminal throat cancer, metastasised to his chest:

"I'm saddened to read this. There's not much that anyone can say really but that we support you and your father for whatever time you two can share".

Empathy messages comprised an understanding or comprehension of the situation of the support seekers, and often with their own comparison of the experience. For example, Elbert responded to another member who was feeling stressed because of waiting for MRI scan results:

"I know how hard it can be to wait on your scans".

Physical affection messages appeared to symbolise virtual physical contact when posted by members. Given that there is no real contact which can take place in online groups, virtual acts posted by support providers were constructed as proxies for physical affection. For example, Elizabeth posted: "Big hugs".

In addition, some respondents sent expressive emotions (emoticons) rather than writing specific words. These emoticons have been included under this dimension and even though they are visual cues of communication, the actual effect of emoticons on meaning in electronic communication appears to be under-researched. In this study we interpreted the emoticons as a means of focusing the recipient on the meaning when communicating virtually. Examples of the different emoticons and their implied meanings are:

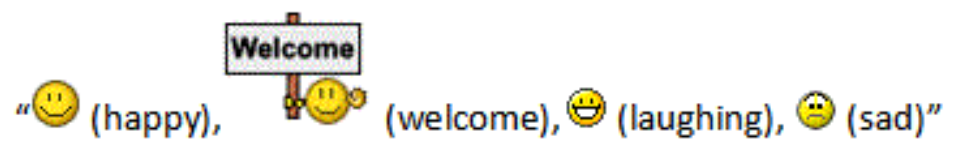


Messages that were coded as expression of care, prayer and relationship were present but in a lower percentage. No messages could be coded as "confidentiality" in which members promise to ensure that the recipient's issues are kept in confidence. This absence may perhaps be attributed to the confidentiality that has been already secured through the anonymity provided by online groups, or to the fact that members can contact each other directly by email and may reach one-to-one agreement away from the group.

Tangible support. This dimension of social support appeared to be the least frequent dimension among the five main dimensions in our data representing only $2.4 \%$ of the total supporting statements. It included four sub-dimensions, and while no messages could be coded under the "perform indirect task", only a few messages were coded under the three remaining sub-dimensions. Most of these messages were coded under "express willingness", in which the supporters experienced willingness to assist the support seekers. A good example was provided by Peter who offers to respond personally:

"I am happy to share my experiences with you, so if you would like to know more, please feel free to pm me and I'll give you my email address".

Uncoded messages. There were 71 statements that could not be coded using the study coding framework. These statements were thematically analysed. We arrived at the following three themes of social interaction: Question/ comment $(n=33)$, expression of gratitude $(n=13)$, and humour $(n=6)$. The remaining 19 statements did not contain any kind of support and were therefore excluded.

\section{Question/ comment}

These messages involved questions or comments that included hidden support such as expression of interest, advice or care for the person. Some participants asked questions illustrating that they were interested in the situation and wanted to know more.

Susan:

"My question is what stage was it? I am assuming no lymph nodes were involved, and that you probably had scans, but did you have any scans to make sure no lymph nodes were involved? Also was it a partial glossectomy or a hemi-glossectomy?"

The advice expressed in these questions was not direct advice, as in the case of the existing advice code, but came in the form of a question intended to give indirect advice. For example Becky posted: "Have you considered having a talk with the source that started this whole thing?" and some questions like Geoffrey's involved expressions of care for the person: "Will you be having any other treatment such as radiation? It wasn't [sic] that long ago, how is your healing coming along?"

Some replies were interpreted as rhetorical comments:

Graham:

"The tagline of this video reminds me of the OCF forum members but with a twist: Instead of the video's "ordinary people with extraordinary dreams", IMO we are "extraordinary people with ordinary dreams". (Or at least I dream of "ordinary" pleasures of eating, drinking, talking, etc.) And who here would not trade their "new normal" for their old "ordinary?"

\section{Expression of gratitude}

These messages included direct thanks for the recipients regarding their participation or posting specific messages. As a kind of behaviour that acknowledges the actions of others, exchanging such messages appeared to have positive outcomes on promoting caring relationships between members in the online groups. In response to Billy posting his full cancer journey, Caroline simply wrote: "Thank you for joining the site and sharing your story". 


\section{Humour}

These messages had a tendency to provoke laughter and provide amusement. Harley responded to Josh who had finished his treatment for tonsil cancer, but was still worried about his first follow up:

Harley:

"Dang the appendix was a real thriller of a complication. I'm kind of reminded of the famous Mark Twain saying "when you're up to your ass in alligators, it's hard to remember your original intention was to drain the swamp."

\section{Social Support Sought: Analysis of Support-Seeking Messages}

Out of the 87 support-seeking messages, approximately 193 statements were coded using the framework. Some statements with a repeated dimension of support found in the same support-seeking message were counted only once and nine statements were excluded. Subsequently, the final number of statements that contained the seeking of at least one sub-dimension of social support was 184. Table 4 shows the frequency of sought social support.

Table 4. Frequency of Sought and Expressed Social Support in Support-Seeking Messages.

\begin{tabular}{lll}
\hline Sought support & Number of messages & \% of messages \\
\hline Seeking informational support & 47 & 25.5 \\
Seeking wellbeing information & 7 & 3.8 \\
Seeking emotional support & 23 & 12.5 \\
Seeking esteem support & 7 & 3.8 \\
Seeking network support & 0 & 0.0 \\
Seeking tangible support & 2 & 1.1 \\
Sharing personal experiences & 58 & 31.5 \\
Expression of gratitude & 26 & 14.1 \\
Congratulations & 0 & 0.0 \\
Expressions of care & 2 & 1.1 \\
Encouragement & 12 & 6.5 \\
\hline Total & 184 & 100 \\
\hline
\end{tabular}

Table 4 illustrates that nine out of the eleven items of social support seeking were found, although with significant variation across the items. The most frequent dimension of support was informational support which was sought by about a quarter of the members, followed by emotional support (12.5\%). The third most frequent was esteem support representing 3.8\%. These frequencies were consistent with those seen in the support-offering messages. Only two support-seeking messages were coded in the seeking tangible assistance dimension, and no messages were coded under seeking network support.

Statements that were coded as "seeking informational support" included specific questions regarding the condition of H\&N cancer in order to obtain factual information, seek advice or suggestions, or to help evaluate a certain situation. Anna had a history of throat cancer and was worried because of the appearance of new symptoms that she was experiencing; rash in the chest area, after sharing she asked:

"Has anyone had any experience with recurring throat cancer? I am interested in knowing if the rash has anything to do with it also".

Messages that were coded as "seeking emotional support" are those in which members, exhibited emotional or psychological weakness and needed comfort due to their condition or the condition of their 
family member. Barry had throat cancer and was told by the consultant that the treatment may make him permanently unable to speak:

Barry:

"How the heck does one FUNCTION at all in society at large without speaking? You guys have been my rock for many years and I know some of you have SOMEthing that I can look upon as "positive" coming out of this. The only thing I can come up with is that "at least I won't have to go around sounding like THIS anymore!" :-) (I speak with a very "gravelly" barely understandable voice right now)."

In the messages that were coded as "seeking esteem support", members were seeking validation for their perspective or were seeking relief from blame when they felt guilty regarding a specific situation. Jacob is a caregiver and posted a message regarding Peter who had terminal tongue cancer that had metastasised to his lungs and was sent home because nothing more could be done for him. Peter wanted chemotherapy and Jacob poses an ethical dilemma which focuses on social justice and hints at the difficult position that carers sometimes find themselves when supporting individuals:

"We think his wishes should be respected, even if it's risky. It would appear that the greatest risk is not doing anything, since that seems to lead to certain death. Aren't doctors obliged to follow the patient's wishes?"

Approximately one third of participants shared their personal experiences with $\mathrm{H} \& \mathrm{~N}$ cancer or the experiences of their family members. Messages coded under this category included those in which members shared their personal conditions, feelings and thoughts related to H\&N cancer with others initially and spontaneously. Some members posted their experience as an introduction for seeking other kinds of support, whereas others only posted their experience. David shares his less than positive experiences, but still has hope:

David:

"Stage 4 cancer [...]. Had chemo and radiation which resulted in pneumonia and 2 other fungal diseases of the lung. The latest PET scan was clear and except for the lung infections I am moving forward. I lost $70 \mathrm{lbs}$. Before this I was extremely athletic [...] Now a pile of bones with skin. Pain in my joints keeps me down, but I'm alive."

Approximately $15 \%$ of the total messages displayed "expression of gratitude" in which members expressed straightforward thankfulness for the recipients either initially or because of their previous support. Angela after seeking information support, posted: "Thank you in advance for any advice".

Encouragement messages included sending hope and confidence to the recipients; these were usually located after sharing a personal experience or seeking other dimensions of support. After seeking emotional support, Amy wrote: "I wish you all the best of luck and I am hoping and praying for all of us". However, only a few messages $(1.1 \%)$ were coded as "expression of care" and no messages could be coded as "congratulations".

\section{Discussion}

The aim of the present study was to assess the types and frequency of social support, sought and offered, within OSGs for H\&N cancer. This study intended to assess the characteristics of the communication between users of online H\&N cancer groups.

The content analysis of the messages provided through the 18 selected H\&N cancer OSGs suggested that these groups were used by people to seek and offer a variety of dimensions of support, in particular informational and emotional. The predominance of these two dimensions of support is consistent with previous research into social support for other health issues, in both face-to-face and OSGs, including eating disorders (Winzelberg, 1997), disability (Braithwaite et al., 1999), torn knee ligament (Preece, 1999), diabetes (Loader, Muncer, Burrows, Pleace, \& Nettleton, 2002), Irritable Bowel Syndrome (Coulson, 2005), Huntington's disease (Coulson et al., 2007), HIV/AIDS (Coursaris \& Liu, 2009; Mo \& 
Coulson, 2008), adolescents with cancer (Elwell, Grogan \& Coulson, 2011), and families affected by childhood cancer (Coulson \& Greenwood, 2012).

In previous studies, the predominance of informational support exceeded that of emotional support in some (Coulson, 2005; Coulson et al., 2007; Coursaris \& Liu, 2009; Loader et al., 2002; Mo \& Coulson, 2008; Winzelberg, 1997) whereas other studies found the opposite (Braithwaite et al., 1999; Preece, 1999). This study adds to existing knowledge because it illustrates that OSGs can enable members who cannot attend face-to-face groups to experience some social interaction and regain elements of their identity, which enhances their emotional coping. For example, people with H\&N cancer who experience speech deficits can still communicate using the written word online in the comfort of their own home. Similarly, others for whom their facial appearance is a barrier, either through societal attitudes, their own lack of confidence, or a mixture of the two can effect communication without worrying about their facial appearance. Whether online interaction can develop coping for future face-to-face interaction is something that at present is unknown. It does however appear that OSGs can be particularly beneficial in terms of maintaining some social interaction for people with $\mathrm{H} \& \mathrm{~N}$ cancer compared with other cancers and helps mediate the challenges of trying to attend face-to-face support groups. This study supports previous studies but it also adds methodological refinement by enriching the coding scheme through new categories of social support exchanged in the H\&N cancer OSGs and modifying the definitions of existing sub-dimensions in the coding frameworks (see the strengths section). This has not been identified in previous OSG research.

Informational support was the most frequent dimension of social support, and this was consistent with the behaviour of people with all cancers using the internet; it is estimated that $30 \%$ of cancer patients use the Internet to obtain cancer information (Helft, Hlubocky, \& Daugherty, 2003). This may be because some patients value having access to the stories of others as it enables them to identify with a similar other and provides them with emotional support, information, reassurance, and practical advice (Rozmovits \& Ziebland, 2004).

The results of the current study suggest that highly factual or technical information (labelled as "Teaching") was supplied by members of OSGs for H\&N cancer representing $9.5 \%$ of the total supportoffering messages. This type of informational support was supplied by members of OSGs in previous studies representing $20 \%$ of the messages posted to OSGs for people with Huntington's disease (Coulson et al., 2007), 5.9\% and $9.7 \%$ of messages that were posted to HIV/AIDS-related OSGs in two different studies respectively (Coursaris \& Liu, 2009; Mo \& Coulson, 2008). Presence of this type of informational support in OSGs can highlight the need to consider the quality and accuracy of the information provided. The validity of such factual information is an important question for further research, particularly in relation to groups run by lay people.

Members of online H\&N cancer-OSGs supplied other sub-dimensions of informational support. For example, they supplied advice to members who were struggling to cope with their condition. They also tried to redefine or appraise the negative situations that related to the consequences of H\&N cancer and its treatments. Approximately $45 \%$ of members who provided different types of support shared their personal experiences or the experiences of their family member with H\&N cancer. Many wrote extensively and openly about their condition. We can suggest that this may be attributed to the anonymity provided in online groups. Anonymity may be particularly beneficial for individuals who perhaps cannot participate in face-to-face support groups because of geographic considerations, the debilitating effects of illness, or in the case of H\&N cancer because their voice and speech may be affected, alternatively, they may have facial impairments as a result of surgery. It may also be that a text based communication medium removes people from immediate face-to-face interaction and this makes sharing easier (Broom, 2005). The reasons appear to be complex and there may be many factors why people appear to find a virtual community an easier and safer place to discuss their experiences of H\&N cancer which supports previous studies on cancer generally (Finn, 1999; Reeves, 2000; Walther \& Boyd, 2002; White \& Dorman, 2001). It does not however explain the depth of the relationships that are formed through OSGs and the reasons why some people may lurk and others engage for extended periods.

The second most frequently offered dimension of social support among members of online H\&N cancer groups was emotional support. The most frequent supporting behaviour under this dimension was encouragement which appeared from the provision of hope and confidence for the recipients. Members of these online groups acknowledged the feelings of the recipients, expressed concern, and prayed with them as well as expressing sorrow for the situations of recipients with H\&N cancer. This may, 
subsequently, have positive influences in the coping process with this disease (Helgeson \& Cohen, 1996; Kim, Han, Shaw, McTavish, \& Gustafson, 2010).

The key function of esteem support supplied by members of the online groups appeared to be the positive assessment of the members by providing compliments such as congratulations and other similar expressions as well as emphasising their ability to cope with stressful situations associated with cancer. The second function for this dimension of support appeared to be validating the perceptions and views of the participants by expressing agreement and highlighting similar concerns to them. This kind of support was found to be exchanged in OSGs for other health conditions such as HIV/AIDS and childhood cancer to provide the same functions as found in this study (Coulson et al., 2007; Coulson \& Greenwood, 2012; Coursaris \& Liu, 2009; Mo \& Coulson, 2008).

The role of network support provided by members of the online groups appeared to provide a common place for recipients to explain all kinds of problems associated with this disease. The availability of this kind of support appeared to be highlighted particularly by older members responding to new members. A relatively low frequency of network support was observed in the present data. This may be because this dimension of support is of particular importance at the time people join to support new members in connecting with the online group. However, after being a member for a short time, the need for this dimension of support was lessened and a route opened for more important dimensions and subdimensions of support (Coulson et al., 2007).

The least frequent dimension of support in the present data was tangible support. This again was comparable to previous studies that used a similar methodology (content analysis) (Coulson, 2005; Coulson et al., 2007; Coursaris \& Liu, 2009; Mo \& Coulson, 2008), in which tangible support was reported to be the least frequently offered and sometimes was quite rare. This low frequency can be attributed to the nature of communications within online groups, which may reduce the chance of this kind of support.

In regard to support seeking, the findings were consistent with that of support provision. The most frequently sought or offered dimension of support was informational support followed by emotional and then esteem support. The consistency of offering support with seeking support was also noticed in one previous study (Coursaris \& Liu, 2009). This consistency may indicate that support providers offer support according to the need of support seekers, but the depth of exploration by engaging participants directly may have biased this suggestion. For example, in a study investigating satisfaction in cancer OSGs, receiving informational or emotional support generally predicted satisfaction positively; users expressed less satisfaction when they sought informational support but received emotional support and there was a tendency for users to express more satisfaction when they sought and received informational support, whereas users were equally satisfied with emotional and informational support after seeking emotional support (Vlahovic, Wang, Kraut, \& Levine, 2014).

Policy may need to be developed that acknowledges the role of support, in that it may have a positive impact in meeting the psychosocial needs of patients as well as preserving, restoring, and promoting physical and emotional health. At present, much of the oral health research is positioned within a biomedical framework and more consideration of psychosocial needs and development of OSGs with people with H\&N cancer may provide a more consistent tool. Every patient should have a holistic needs assessment which includes access to high quality support networks as there are significant psychological and emotional challenges in coping with potential disfigurement and the consequences of treatment (Baker, 1992; Callahan, 2004; Katz, Irish, Devins, Rodin, \& Gullane, 2003). Patients should also be directed to support groups, either face-to-face or online and information to enable them to cope with the consequences of their treatment (NICE, 2004).

\section{Study Strengths and Limitations}

In order to ensure reliability of the data, some important measures were taken. For example, we decided to gather our data from different H\&N cancer-OSGs and not merely from one. Only the active groups were included and the selection was from the most recent year at the time of data collection (2011).

Moreover, for support-providing messages, the study used a pre-validated coding framework, which has been successfully used for content analysis of online messages. In addition, both of the coding frameworks used in the current study offered clear and well-defined content categories so that a high agreement level was achieved when randomly selected messages from the entire data were coded by others. 
The study produced three new sub-dimensions of social support (humour, expression of gratitude and question/comment) from the few statements that could not be coded by the coding framework for the support-offering messages. Although messages coded under these three new sub-dimensions were few, future studies should validate their inclusion within the coding framework. That is, "humour", "expression of gratitude" and "question/comment" should be added as new sub-dimensions to emotional support, esteem support and informational support respectively.

Similarly, some modifications were introduced to the definitions of two of the existing sub-dimensions in the coding framework for the support-offering messages (validation and physical affection). Firstly, the results suggest that some support-offering messages expressed validation and agreement with previous respondents other than the posters of the original message. This necessitated slight modifications to the definition of "validation sub-dimensions" of social support within the coding framework to include such kinds of messages. Therefore, the new definition of this item is messages involving acknowledgment or agreement with the recipient's opinion or previous respondents on the situation related to H\&N cancer including their emotions, actions, beliefs or thoughts. Secondly, some respondents sent expressive icons (emoticons) rather than writing specific words. These emoticons have been included as proxies of physical affection in this sub-dimension of social support. This has also necessitated slight modifications to the definition of this sub-dimension in the coding framework. The new definition for this sub-dimension will include messages that offer physical contact, including hugs, kisses, hand holding, shoulder patting, as well as expressive emoticons. Both modifications need to be validated in future studies with OSGs

The majority of members appeared to belong to developed countries such as the USA, UK and Canada in which English language is the main and official language. Not surprisingly, this is because the present study dealt with online groups that were conducted in English. However, the generalisability of our results to represent H\&N cancer groups in other languages or in developing countries has not been tested. This is despite a higher incidence of H\&N cancer reported in developing countries.

Pseudonyms were used and identifiable details removed or altered. Even though as many steps were taken to protect participants, there was still a small risk of inferred identification, with respondents recognizing their own words or those of others from a given forum. In spite of these limitations, the chosen methodology provided an opportunity to investigate how people (and sometimes their carers/family members) with H\&N cancer participate in OSGs.

\section{Conclusion}

Head and neck cancer-OSGs appear to provide a source of cancer-related informational and emotional support for people with $\mathrm{H} \& \mathrm{~N}$ cancer. They may further provide new opportunities for people to receive social support. This paper calls for more attention to be given to such groups, paying attention to the quality and reliability of information offered to people with H\&N cancer, their caregivers, and the wider public.

Future research may consider the quality and quantity of online relationships for OSG users with H\&N cancer and whether this has an impact on perceived support and coping. In addition, the validity and accuracy of the highly factual information that was found in the OSGs can be an important area of focus for further research, particularly in relation to groups run by and for lay people. Future research may also examine the generalisability of the findings of this study in representing face-to-face groups and whether OSGs can be sufficient when face-to-face support groups are lacking. Another research area may be to compare and contrast the benefits of offline and online support for people with H\&N cancer and the extent of the impact on their families and carers. Finally, assessment of the support needs and coping mechanisms of patients across the cancer pathway, particularly for H\&N cancer, may provide greater insights into the type of support needed with the aim of enabling patient choice and empowerment.

\section{Notes}

1. Participants' names have been changed to protect their privacy.

2. Spelling and grammatical errors in the quotes are left as in the original. 


\section{References}

Agarwal, M., Hamilton, J. B., Crandell, J. L., \& Moore, C. E. (2010). Coping strategies of African American head and neck cancer survivors. Journal of Psychosocial Oncology, 28, 526-538.

http://dx.doi.org/10.1080/07347332.2010.498456

Al-Azri, M., Al-Awisi, H., \& Al-Moundhri, M. (2009). Coping with a diagnosis of breast cancer-literature review and implications for developing countries. The Breast Journal, 15, 615-622.

http://dx.doi.org/10.1111/j.1524-4741.2009.00812.x

Antonovsky, A. (1979). Health, stress and coping. San Fransico: Josset-Bass.

Baker, C. (1992). Factors associated with rehabilitation in head and neck cancer. Cancer Nursing, 15, 395-400. http://dx.doi.org/10.1097/00002820-199212000-00002

Berkman, L. F., \& Syme, S. L. (1979). Social networks, host resistance and mortality: A nine-year followup study of Alameda County residents. American Journal of Epidemiology, 109, 186-204.

Braithwaite, D. O., Waldron, V. R., \& Finn, J. (1999). Communication of social support in computermediated groups for people with disabilities. Health Communication, 11, 123-151.

http://dx.doi.org/10.1207/s15327027hc1102_2

Broom, A. (2005). The eMale: Prostate cancer, masculinity and online support as a challenge to medical expertise. Journal of Sociology, 41, 87-104. http://dx.doi.org/10.1177/1440783305050965

Callahan, C. (2004). Facial disfigurement and sense of self in head and neck cancer. Social Work in Health Care, 40(2), 73-87. http://dx.doi.org/10.1300/J010v40n02_05

Chaturvedi, S. K., Shenoy, A., Prasad, K. M. R., Senthilnathan, S. M., \& Premlatha, B. S. (1996). Concerns, coping and quality of life in head and neck cancer patients. Supportive Care in Cancer, 4, 186190. http://dx.doi.org/10.1007/BF01682338

Chueh, Y., Lin, H., Yu, C., Cheng, S., Chen, I., Liao, C., . . Chang, J. (2009). Social support service impact to the anxiety and depression of oral cavity cancer patients in Taiwan. European Journal of Cancer Supplements, 7, 493-493. http://dx.doi.org/10.1016/S1359-6349(09)71671-4

Cobb, S. (1976). Social support as a moderator of life stress. Psychosomatic medicine, 38, 300-314. http://dx.doi.org/10.1097/00006842-197609000-00003

Coulson, N. S. (2005). Receiving social support online: An analysis of a computer-mediated support group for individuals living with irritable bowel syndrome. CyberPsychology \& Behavior, 8, 580-584.

http://dx.doi.org/10.1089/cpb.2005.8.580

Coulson, N. S., Buchanan, H., \& Aubeeluck, A. (2007). Social support in cyberspace: A content analysis of communication within a Huntington's disease online support group. Patient Education and Counseling, 68, 173-178. http://dx.doi.org/10.1016/j.pec.2007.06.002

Coulson, N. S., \& Greenwood, N. (2012). Families affected by childhood cancer: An analysis of the provision of social support within online support groups. Child Care Health and Development, 38, 870877. http://dx.doi.org/10.1111/j.1365-2214.2011.01316.x

Coursaris, C. K., \& Liu, M. (2009). An analysis of social support exchanges in online HIV/AIDS self-help groups. Computers in Human Behavior, 25, 911-918. http://dx.doi.org/10.1016/j.chb.2009.03.006

Cutrona, C. E., \& Suhr, J. A. (1992). Controllability of stressful events and satisfaction with spouse support behaviors. Communication Research, 19, 154-174.

http://dx.doi.org/10.1177/009365092019002002 
de Leeuw, J. R. J., de Graeff, A., Ros, W. J. G., Blijham, G. H., Hordijk, G. J., \& Winnubst, J. A. M. (2000). Prediction of depressive symptomatology after treatment of head and neck cancer: The influence of pretreatment physical and depressive symptoms, coping, and social support. Head \& Neck, 22, 799-807. http://dx.doi.org/10.1002/1097-0347(200012)22:8<799::AID-HED9>3.0.CO;2-E

de Leeuw, J. R. J., de Graeff, A., Ros, W. J. G., Hordijk, G. J., Blijham, G. H., \& Winnubst, J. A. M. (2000). Negative and positive influences of social support on depression in patients with head and neck cancer: $A$ prospective study. Psycho-Oncology, 9, 20-28. http://dx.doi.org/10.1002/(SICI)10991611(200001/02)9:1<20: :AID-PON425>3.0.CO;2-Y

Dropkin, M. J. (2001). Anxiety, coping strategies, and coping behaviors in patients undergoing head and neck cancer surgery. Cancer Nursing, 24, 143-148. http://dx.doi.org/10.1097/00002820-20010400000010

Durkheim, E. (1951). Suicide: A study in sociology. London: Free Press.

Elani, H. W., \& Allison, P. J. (2011). Coping and psychological distress among head and neck cancer patients. Supportive Care in Cancer, 19, 1735-1741. http://dx.doi.org/10.1007/s00520-010-1013-8

Elani, H., Edgar, L., \& Allison, P. J. (2009). Anxiety, depression and coping in head and neck cancer patients. Oral Oncology 3, 61. http://dx.doi.org/10.1016/j.00s.2009.06.101

Elwell, L., Grogan, S., \& Coulson, N. (2011). Adolescents living with cancer the role of computer-mediated support groups. Journal of Health Psychology, 16, 236-248.

http://dx.doi.org/10.1177/1359105310371398

Eysenbach, G., Powell, J., Englesakis, M., Rizo, C., \& Stern, A. (2004). Health related virtual communities and electronic support groups: Systematic review of the effects of online peer to peer interactions. British Medical Journal, 328, 1166-1170A. http://dx.doi.org/10.1136/bmj.328.7449.1166

Eysenbach, G., \& Till, J. E. (2001). Ethical issues in qualitative research on internet communities. British Medical Journal, 323, 1103-1105. http://dx.doi.org/10.1136/bmj.323.7321.1103

Ferlay, J., Soerjomataram, I., Dikshit, R., Eser, S., Mathers, C., Rebelo, M., . . Bray, F. (2015). Cancer incidence and mortality worldwide: Sources, methods and major patterns in GLOBOCAN 2012.

International Journal of Cancer, 136, E359-386. http://dx.doi.org/10.1002/ijc.29210

Finn, J. (1999). An exploration of helping processes in an online self-help group focusing on issues of disability. Health \& Social Work, 24, 220-231. http://dx.doi.org/10.1093/hsw/24.3.220

Flicker, S., Haans, D., \& Skinner, H. (2004). Ethical dilemmas in research on internet communities. Qualitative Health Research, 14, 124-134. http://dx.doi.org/10.1177/1049732303259842

Gamba, A., Romano, M., Grosso, I. M., Tamburini, M., Cantu, G., Molinari, R., \& Ventafridda, V. (1992). Psychosocial adjustment of patients surgically treated for head and neck cancer. Head \& Neck, 14, $218-$ 223. http://dx.doi.org/10.1002/hed.2880140309

Haahr, M. (1998). True random number services: Introduction to randomness and random numbers [Web log comment]. Retrieved from http://www.random.org/randomness/

Hagedoorn, M., \& Molleman, E. (2006). Facial disfigurement in patients with head and neck cancer: The role of social self-efficacy. Health Psychology, 25, 643-647. http://dx.doi.org/10.1037/0278-

6133.25 .5 .643

Helft, P. R., Hlubocky, F., \& Daugherty, C. K. (2003). American oncologists' views of internet use by cancer patients: A mail survey of American Society of Clinical Oncology members. Journal of Clinical Oncology, 21, 942-947. http://dx.doi.org/10.1200/JCO.2003.08.007 
Helgeson, V. S., \& Cohen, S. (1996). Social support and adjustment to cancer: Reconciling descriptive, correlational, and intervention research. Health Psychology, 15, 135-148.

http://dx.doi.org/10.1037/0278-6133.15.2.135

Holt-Lunstad, J., Smith, T. B., \& Layton, J. B. (2010). Social relationships and mortality risk: A metaanalytic review. PLoS medicine, 7(7). e1000316. http://dx.doi.org/10.1371/journal.pmed.1000316

Houston, V., \& Bull, R. (1994). Do people avoid sitting next to someone who is facially disfigured? European Journal of Social Psychology, 24, 279-284. http://dx.doi.org/10.1002/ejsp.2420240205

Howren, M. B., Christensen, A. J., \& Karnell, L. H. (2011). Influence of pre-treatment social support on post treatment depression and health - related quality of life in patients with head and neck cancer. Annals of Behavioral Medicine; 41(Suppl. 1), S59 -S59. http://dx.doi.org/10.1002/hed.23029

Karim-Kos, H. E., de Vries, E., Soerjomataram, I., Lemmens, V., Siesling, S., \& Coebergh, J.W. (2008). Recent trends of cancer in Europe: A combined approach of incidence, survival and mortality of 17 cancer sites since the 1990s. European Journal of Cancer, 44, 1345-89.

http://dx.doi.org/10.1016/j.ejca.2007.12.015

Karnell, L. H., Christensen, A. J., Rosenthal, E. L., Magnuson, J. S., \& Funk, G. F. (2007). Influence of social support on health-related quality of life outcomes in head and neck cancer. Head \& Neck, 29(2), 143-146. http://dx.doi.org/10.1002/hed.20501

Katz, M. R., Irish, J. C., Devins, G. M., Rodin, G. M., \& Gullane, P. J. (2003). Psychosocial adjustment in head and neck cancer: The impact of disfigurement, gender and social support. Head \& Neck, 25, $103-12$. http://dx.doi.org/10.1002/hed.10174

Kim, J., Han, J. Y., Shaw, B., McTavish, F., \& Gustafson, D. (2010). The roles of social support and coping strategies in predicting breast cancer patients' emotional well-being testing mediation and moderation models. Journal of Health Psychology, 15, 543-552. http://dx.doi.org/10.1177/1359105309355338

Lazarus, R. S. (1976). Psychological stress and the coping process. New York: McGraw-Hill.

Lazarus, R. S., \& Folkman, S. (1984). Stress, appraisal, and coping. New York: Springer.

List, M. A., Rutherford, J. L., Stracks, J., Haraf, D., Kies, M. S., \& Vokes, E. E. (2002). An exploration of the pretreatment coping strategies of patients with carcinoma of the head and neck. Cancer, 95, 98-104. http://dx.doi.org/10.1002/cncr.10653

Loader, B. D., Muncer, S., Burrows, R., Pleace, N., \& Nettleton, S. (2002). Medicine on the line? Computer-mediated social support and advice for people with diabetes. International Journal of Social Welfare, 11, 53-65. http://dx.doi.org/10.1111/1468-2397.00196

McDonough, E. M., Boyd, J. H., Varvares, M. A., \& Maves, M. D. (1996). Relationship between psychological status and compliance in a sample of patients treated for cancer of the head and neck. Head \& Neck, 18, 269-276. http://dx.doi.org/10.1002/(SICI)1097-0347(199605/06)18:3<269::AIDHED9>3.0.CO;2-Y

Mo, P. K. H., \& Coulson, N. S. (2008). Exploring the communication of social support within virtual communities: A content analysis of messages posted to an online HIV/AIDS support group. CyberPsychology \& Behavior, 11,371-374. http://dx.doi.org/10.1089/cpb.2007.0118

NICE (2004). Improving outcomes in head and neck cancers: The manual. National Institute for Clinical Excellence. Retrieved from http://www.nice.org.uk/guidance/csghn/evidence/improving-outcomes-inhead-and-neck-cancers-the-manual 2

Petticrew, M., Bell, R., \& Hunter, D. (2002). Influence of psychological coping on survival and recurrence in people with cancer: Systematic review. British Medical Journal, 325, 1066-1069.

http://dx.doi.org/10.1136/bmj.325.7372.1066 
Preece, J. (1999). Empathy online. Virtual Reality, 4, 74-84. http://dx.doi.org/10.1007/BF01434996

Reeves, P. M. (2000). Coping in cyberspace: The impact of internet use on the ability of HIV-positive individuals to deal with their illness. Journal of Health Communication, 5(Suppl. 1), 47-59.

http://dx.doi.org/10.1080/10810730050019555

Rogers, S. N., Hannah, L., Lowe, D., \& Magennis, P. (1999). Quality of life 5-10 years after primary surgery for oral and oro-pharyngeal cancer. Journal of Cranio-Maxillofacial Surgery, 27, 187-191.

http://dx.doi.org/10.1016/S1010-5182(99)80049-3

Rozmovits, L., \& Ziebland, S. (2004). What do patients with prostate or breast cancer want from an Internet site? A qualitative study of information needs. Patient Education and Counseling, 53, 57-64. http://dx.doi.org/10.1016/S0738-3991(03)00116-2

Sherman, A. C., Simonton, S., Adams, D. C., Vural, E., \& Hanna, E. (2000). Coping with head and neck cancer during different phases of treatment. Head \& Neck, 22, 787-793. http://dx.doi.org/10.1002/10970347(200012)22:8<787::AID-HED7>3.0.CO;2-R

Stanton, A. L., Danoff-Burg, S., Cameron, C. L., Bishop, M., Collins, C. A., Kirk, S. B., ... Twillman, R. (2000). Emotionally expressive coping predicts psychological and physical adjustment to breast cancer. Journal of Consulting and Clinical Psychology, 68, 875-882. http://dx.doi.org/10.1037/0022-

006X.68.5.875

Stanton, A. L., Revenson, T. A., \& Tennen, H. (2007). Health psychology: Psychological adjustment to chronic disease. Annual Review of Psychology, 58, 565-592.

http://dx.doi.org/10.1146/annurev.psych.58.110405.085615

Tolentino E. D. S., Centurion, B. S., Ferreira, L. H., Souza, A. P., Damante, J. H., \& Rubira-Bullen, I. R. (2011). Oral adverse effects of head and neck radiotherapy: Literature review and suggestion of a clinical oral care guideline for irradiated patients. Journal of Applied Oral Science, 19, 448-54.

http://dx.doi.org/10.1590/S1678-77572011000500003

van Cann, E. M., Dom, M., Koole, R., Merkx, M. A. W., \& Stoelinga, P. J. W. (2005). Health related quality of life after mandibular resection for oral and oropharyngeal squamous cell carcinoma. Oral Oncology, 41, 687-693. http://dx.doi.org/10.1016/j.oraloncology.2005.03.001

Vidhubala, E., Ravikannan, R., Mani, C. S., Karthikesh, M., \& Latha (2006). Coping preferences of head and neck cancer patients - Indian context. Indian journal of cancer, 43, 6-11.

http://dx.doi.org/10.4103/0019-509X.25768

Vlahovic, T. A., Wang, Y., Kraut, R. E., \& Levine, J. M. (2014). Support matching and satisfaction in an online breast cancer support community. In CHI '14 Proceedings of the SIGCHI Conference on Human Factors in Computing Systems (pp. 1625-1634). http://dx.doi.org/10.1145/2556288.2557108

Walther, J. B., \& Boyd, S. (2002). Attraction to computer-mediated social support. In: C. A. Lin \& D. Atkin (Eds.), Communication technology and society: Audience adoption and uses (pp. 153-188). Cresskill, NJ: Hampton Press.

Wang, Y. C., Kraut, R., \& Levine, J. M. (2012). To Stay or leave? The relationship of emotional and informational support to commitment in online health support groups. In Proceedings of the ACM 2012 conference on Computer Supported Cooperative Work (pp. 833-842). ACM.

http://dx.doi.org/10.1145/2145204.2145329

White, M. H., \& Dorman, S. M. (2000). Online support for caregivers - Analysis of an Internet Alzheimer mailgroup. Computers in Nursing, 18, 168-176.

White, M. H., \& Dorman, S. M. (2001). Receiving social support online: Implications for health education. Health Education Research, 16, 693-707. http://dx.doi.org/10.1093/her/16.6.693 
Winzelberg, A. (1997). The analysis of an electronic support group for individuals with eating disorders. Computers in Human Behavior, 13, 393-407. http://dx.doi.org/10.1016/S0747-5632(97)00016-2

\author{
Correspondence to: \\ Eamar Algtewi \\ The Academic Unit of Dental Public Health \\ School of Clinical Dentistry \\ 19 Claremont Crescent \\ University of Sheffield \\ Sheffield \\ United Kingdom \\ S10 2TA
}

Phone: +441142717885

Email: am_hd68(at)yahoo.com

\begin{abstract}
About authors
Eamar E. Algtewi is a researcher at the School of Dentistry, The University of Sheffield, UK since 2011. He has been awarded his PhD from the University in October 2015, having received his Masters in Dental Public Health from the same university in 2009. He has worked as a dentist and lecturer in Libya after receiving his BDS degree from Garyouns University, Libya in 2001. His most recent research examines online social support for people with head and neck cancer.
\end{abstract}
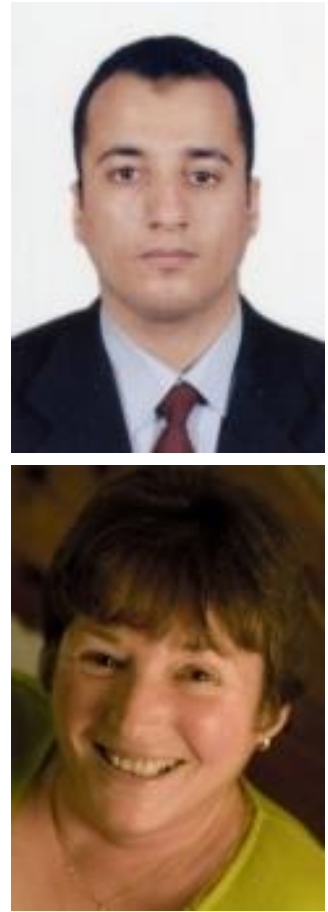

Janine Owens is a Lecturer in Disability and Health and staff member at the School of Dentistry, The University of Sheffield, UK. She is also Research Ethics lead and joined the School in 2005 having previously worked in the Kingdom of Saudi Arabia. Her research interests fall into four areas; disability and marginalised groups, embodiment and experiences of oral health, health promotion, and cultural beliefs and practices related to health.

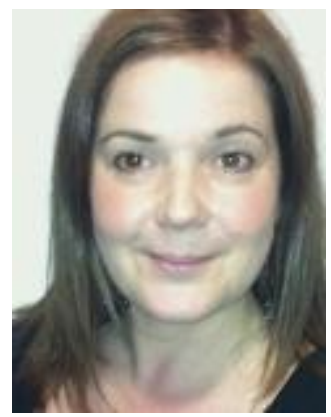

Sarah R. Baker is a professor in Psychology at the School of Dentistry, The University of Sheffield, UK. She joined this School in 2005. Her interest involves psychological adjustment to oral health conditions and their treatment as well as development and evaluation of person-reported outcome measures (PROMs) in dentistry. 